\title{
Mapping of agriculture farms using GPS and GIS technique for precision farming
}

Kishore C. Swain and Chiranjit Singha

Received : 26.03.2018; Revised : 01.08.2018; Accepted : 17.08.2018

See end of the Paper for authors' affiliation

Correspondence to :

Chiranjit Singha

Department of Agricultural

Engineering, Institute of

Agriculture, Visva-Bharti,

Sriniketan (W.B.) India

Email :singha.chiranjit@

gmail.com
- ABSTRACT : Over the past several years, an increasing number of large-scale agriculture corporations have expressed the requirement for logging their farming operations at a low cost. Hence, in precession agriculture this system as alternative to the field verification to recording and collecting farming data. The technical and economic feasibility of applying GPS equipped with GIS technology to the system was ascertained. In farm land record approach the use of GPS in Agriculture is limited but it is fair to expect wide spread use of GPS in future. One of the primary challenges that farmers have is the lack of knowledge on what crop to plant, as well as where to plant for guaranteed maximum yield. However, modern farming has benefited two fold -it is mechanized and uses great technologies such as the spatial technologies. Evidently, the use of GIS and GPS technologies at your farm is highly beneficial. With such technologies in place, it not only makes it easy to manage the farm, but also guarantees high yields and profits. Therefore, this record keeping farm management system needs to be adoptes these technologies so far, helps in farm management and the creation of new opportunities that are necessary in increasing your profit margins. The field mapping of PSB Agricultural Farm at Sriniketan, West Bengal was carried out using handheld GPS receiver and collecting secondary study area maps and crop practice information. The digitization and mapping was carried out in Arc View software environment is masking out the crop area from other landuses. The various cropping pattern was also recorded and a database was developed for record keeping and making better production decision.

- KEY WORDS : Precision agriculture, GPS, GIS, Field mapping, Record keeping

- HOW TO CITE THIS PAPER : Swain, Kishore C. and Singha, Chiranjit (2018). Mapping of agriculture farms using GPS and GIS technique for precision farming. Internat. J. Agric. Engg., 11(2) : 269-275, DOI: 10.15740/HAS/IJAE/11.2/269-275. Copyright@2018: Hind Agri-Horticultural Society. 